\title{
Long-Term Outcome of Monochorionic Twins after Fetoscopic Laser Therapy Compared to Matched Dichorionic Twins
}

\author{
Ladina Rüegg ${ }^{a}$ Margaret Hüsler ${ }^{a, b}$ Franziska Krähenmann ${ }^{a, b}$ \\ Roland Zimmermann ${ }^{a, b}$ Giancarlo Natalucci ${ }^{c, d, e}$ Nicole Ochsenbein-Kölble ${ }^{a, b}$ \\ aDepartment of Obstetrics, University Hospital Zurich, Zurich City, Switzerland; b Zurich Center for Fetal Diagnosis \\ and Therapy, Zurich, Switzerland; 'Department of Neonatology, University of Zurich and University Hospital Zurich, \\ Zurich, Switzerland; 'Larsson-Rosenquist Centre for Neurodevelopment, Growth and Nutrition of the Newborn, \\ University of Zurich, Zurich, Switzerland; ${ }^{e}$ Child Development Centre, University Children's Hospital Zurich, \\ Zurich, Switzerland
}

\section{Keywords}

Twin-to-twin transfusion syndrome · Fetoscopy · Fetoscopic laser surgery · Monochorionic twins · Dichorionic twins . Long-term outcome $\cdot$ Neurodevelopment

\begin{abstract}
Introduction: The only causal therapy is fetoscopic laser surgery (FLS). The aims of this study were to analyze the longterm outcome of monochorionic twins treated by FLS, including their school career, need for therapy and special aid equipment, and free-time activities, and compare their outcome to matched dichorionic twins. Material and Methods: Among the 57 women treated at a single fetal treatment center between 2008 and 2017 with FLS because of twin-totwin transfusion syndrome, 25 women with 42 children were included in the FLS group. The control group consisted of 16 dichorionic twin pairs matched for birth year, gestational age (GA), birth weight, and sex. The long-term outcome was assessed by a parental questionnaire and a standardized neurodevelopmental examination for children
\end{abstract}

karger@karger.com www.karger.com/fdt

Karger $\stackrel{\text { ' }}{5}$

GOPEN ACCESS
(C) 2020 The Author(s)

Published by S. Karger AG, Basel

This is an Open Access article licensed under the Creative Commons Attribution-NonCommercial-4.0 International License (CC BY-NC) (http://www.karger.com/Services/OpenAccessLicense), applicable to the online version of the article only. Usage and distribution for commercial purposes requires written permission. born before 32 gestational weeks or with a birth weight lower than $1500 \mathrm{~g}$. They were also registered into the Swiss Neonatal Network database. The primary outcome was eventfree survival, defined as normal neurology, behavior, vision, and hearing. The secondary outcomes were school career, need for therapy and special aid equipment, and free-time activities. Results: An event-free survival was found in 32 children $(76 \%)$ in the laser and in 24 children $(75 \%)$ in the control group $(p=0.91)$. Neurological anomalies were found in 5 children (12\%) in the laser group and 3 children (9\%) in the control group $(p=1.00)$. Multiple logistic regression analysis showed that GA at delivery was the only predictive factor for event-free survival. There were no significant differences regarding school career, therapies, or special aid equipment between the 2 groups. We found that children

Giancarlo Natalucci and Nicole Ochsenbein-Kölble shared last authorship.

Presented as oral presentation at the 38th Annual Meeting of the International Fetal Medicine and Surgery Society, October 22-26, 2019, Sils, Switzerland.
Nicole Ochsenbein-Kölble

Clinic of Obstetrics, University Hospital Zurich

Frauenklinikstr. 10

CH-8091 Zurich (Switzerland

nicole.ochsenbein@usz.ch 
without FLS were involved in more free-time activities and needed fewer breaks during physical activity than children with FLS during pregnancy. Conclusion: The outcome of monochorionic twins treated with FLS is comparable to the outcome of dichorionic twins. Long-term neurodevelopment in the cohort was mainly dependent on GA at birth.

(c) 2020 The Author(s)

Published by S. Karger AG, Basel

\section{Introduction}

In a monochorionic-diamniotic pregnancy, an imbalanced blood flow between the 2 fetuses can lead to twinto-twin transfusion syndrome (TTTS) [1]. In almost all placentas of monochorionic twin pregnancies, anastomoses are found; nevertheless, TTTS only occurs in 10$15 \%$ [2]. The risk of fetal death of one or both twins is above $90 \%$ without treatment [3]. Fetoscopic laser coagulation of anastomoses is the only causal therapy and represents the gold standard since Senat et al. [4] presented higher survival rates and a better neurological outcome after laser therapy than sole amniotic fluid reduction [4].

Several studies have presented survival rates after fetoscopic laser surgery (FLS) of 70-90\% for at least 1 child and approximately $40-70 \%$ for 2 children [4-8]. Due to the improving survival rates, the main interest is shifting from survival to the long-term outcome and the neurological development of the surviving children. Several studies showed that the incidence of cerebral injury is lower after FLS than after sole amnion reduction $[4,9$, 10]. A meta-analysis from van Klink et al. [10] even showed a 7-fold higher incidence of severe cerebral injury in TTTS twins treated with amnion reduction than in TTTS twins treated with FLS.

The aims of this study were to analyze the long-term outcome of children treated with FLS, including their school career, the need for special therapy or special aid equipment, and their free-time activities, and compare their outcome to that of dichorionic twins. An understanding of the development of the children over time will provide a more accurate counselling to parents who are diagnosed with TTTS during pregnancy. Further, the long-term outcome is also an important quality control when performing fetoscopic surgery.

\section{Material and Methods}

\section{Study Population}

From 2008 to 2017, a total of 70 FLSs were performed at the Zurich Center for Fetal Diagnosis and Therapy Hospital of Zurich (www.swissfetus.ch). Fifty-seven FLSs were performed due to TTTS. Eligible for the laser group in this retrospective cohort study were children who were treated by FLS and were at least 6 months old. Further inclusion criteria that regarded both the FLS and the control groups were good German language skills and parental informed consent. Thirty-two women could not be included due to either loss of pregnancy $(n=12)$, neonatal death $(n=1)$, loss of follow-up or insufficient German language skills $(n=15)$, still pregnant or children younger than 6 months $(n=3)$, and refusal $(n=1)$. Ultimately, 25 women and 42 children were included as the "laser group" (Fig. 1).

The control group included dichorionic twins matched for birth year ( \pm 2 years), gestational age (GA; \pm 3 weeks), birth weight, and sex. All baseline data were collected from the electronic hospital charts of the mothers and their infants. The following variables were collected from the clinical records: maternal age, parity, ethnicity, and socioeconomic status, defined by a validated 12-point score based on maternal education and paternal occupation - the higher the score, the lower the socioeconomic class, according to Largo et al. [11].

\section{Pregnancy Course}

TTTS was diagnosed based on ultrasound criteria by Quintero et al. [12]. Fetoscopic laser coagulation of the placental anastomoses was performed under regional anesthesia in the first 10 cases and under local anesthesia with analgosedation in the following 47 cases. A fetoscope was inserted through a 10 French trocar through the abdominal wall into the amniotic cavity under constant ultrasound guidance. The anastomoses were selectively coagulated by a YAG laser. Always the same 2 feto-maternal specialists performed the FLS under ultrasound guidance. The Solomon technique [13] has been performed since 2011.

\section{Outcome Parameter}

The primary outcome of this analysis was the event-free longterm development of the children. Within event-free survival, the main focus was set on the neurodevelopmental outcome. An event-free long-term outcome was defined for children who were free of any neurological or behavioral abnormality, and no severe visual or hearing deficiencies.

The neurological outcomes included cerebral palsy (CP), epilepsy, and other sensorimotor deficiencies. CP was clinically diagnosed and classified according to the recommendations of the European Cerebral Palsy Network [14]. Sensorimotor abnormalities included isolated abnormal tone, reflexes, or coordination, which did not meet the criteria for CP.

Outcome evaluation also included the behavioral development of the children, which was assessed using the Strengths and Difficulties Questionnaire (SDQ) filled out by the parents. Children with a GA or weight at birth below 32 weeks or 1,500 g, respectively, were also assessed by means of the Bayley Scales of Infant Development, second edition (BSID-II) [15], and Bayley Scales of Infant and Toddler Development, third edition (BayleyIII) [16], as part of the Swiss Follow-up Program for very preterm infants.

The secondary outcomes were school career (including difficulties in school, such as repeating a school year, need for educational support, speech, and writing), special therapy and requirement of special aid or other assistive equipment, and free-time activities of the children, as assessed by a generic parental ques- 


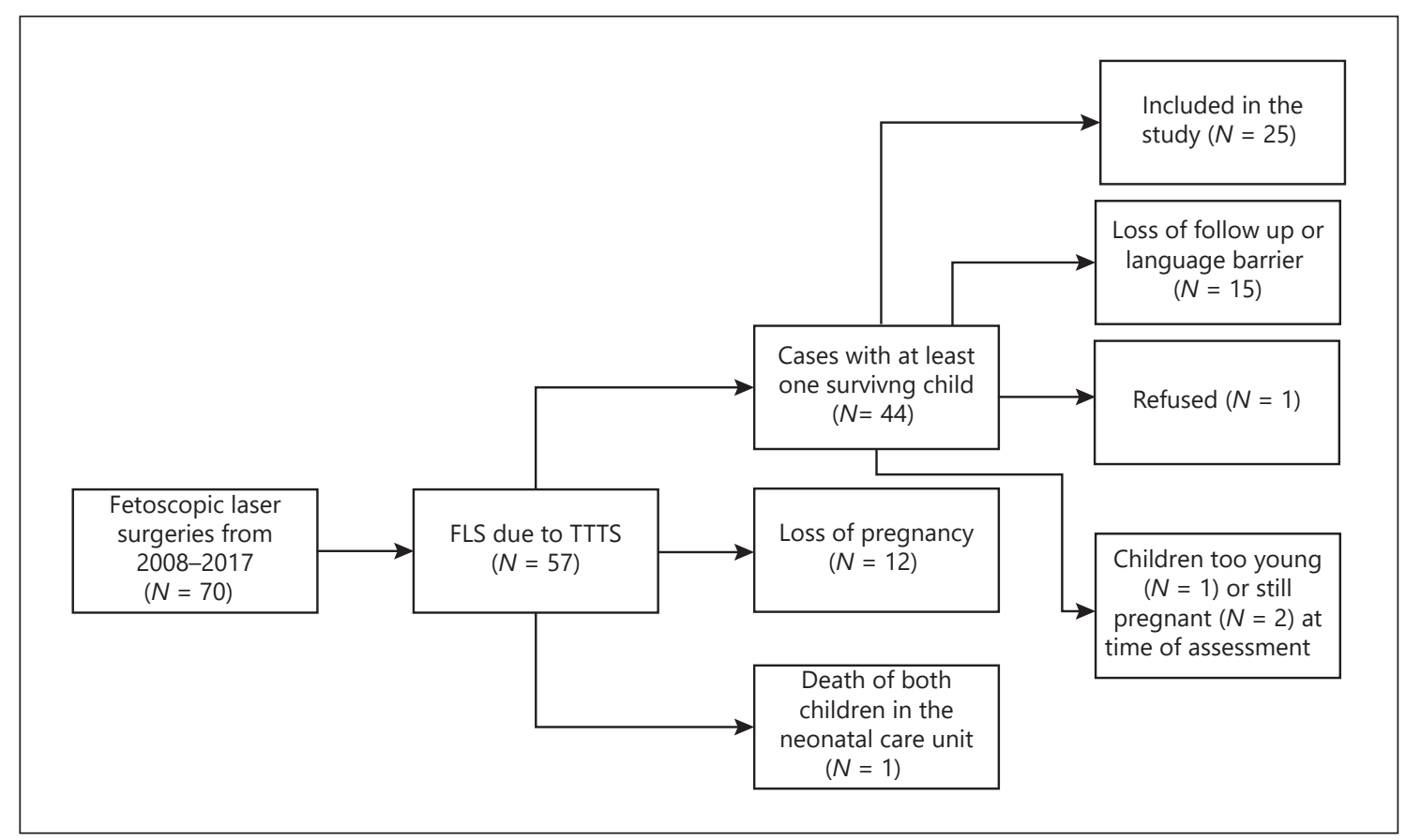

Fig. 1. FLS, fetoscopic laser surgery; TTTS, twin-to-twin transfusion syndrome.

tionnaire. Both primary and secondary outcomes were compared with dichorionic-diamniotic twins, to assess if they differ from twins with TTTS and laser surgery during pregnancy.

\section{Maternal and Neonatal Course}

The following neonatal baseline data of the infants were also collected from the computerized medical records: GA, weight, length, head circumference, umbilical cord $\mathrm{pH}$, and Apgar scores at delivery. The data on the major neonatal morbidities known to be associated with a poor long-term outcome in preterm infants [17] were also collected from the database of the department. These included bronchopulmonary dysplasia, necrotizing enterocolitis, sepsis, retinopathy of prematurity defined as previously published [17], and major brain injury, defined by cerebral ultrasound exam as cystic periventricular leukomalacia and/or intraventricular hemorrhage grade 3 or higher according to the classification of Papile [18].

\section{Pediatric Course and Long-Term Outcome}

Data on the development of the study children were collected by means of a parental questionnaire including a short survey about their children's general health, medication, school situation, therapy (e.g., physiotherapy and speech therapy), any kind of support (e.g., glasses, hearing aid, or walking aid). The parent version of the SDQ was used to assess the behavioral outcome of the study children [19]. The SDQ is a standardized parental, teacher, or self-report questionnaire on behavioral problems of children and adolescents [20,21]. The SDQ consists of 5 sections with 5 questions each, resulting in a total number of 25 questions. Each answer is scored on a scale ranging from 0 (= not true) to 2 (= certainly true). The 5 sections screen for the following behavioral domains: emotional symptoms (e.g., Item 24: "Many fears, easily scared..."), conduct problems (e.g., Item 18: "Often lies or cheats"), hyperactivity/inattention (e.g., Item
10: "Constantly fidgeting or squirming"), peer problems (e.g., Item 19: "Picked on or bullied by other children"), and prosocial behavior (e.g., Item 4: "Shares readily with other children") [19, 20]. Each domain corresponds to a subscale that is computed by adding the scores of all answers of the same section and ranges $0-10$ points, with higher scores indicating more behavioral problems. The prosocial scale shows a reverse direction with lower scores indicating a worse behavioral pattern. Excluding the prosocial scale, the scores for emotional problems, conduct problems, hyperactivity/inattention, and peer relationship problems are summed up to a "total difficulties score," which ranges from 0 to 40 . The "total difficulties scores" ranging from 0 to 13 are classified as normal, scores ranging 14-16 are considered borderline, and scores above 16 are considered abnormal. We combined children in the borderline and abnormal categories into a single "at-risk" category, as we considered the borderline group also to be at risk for behavioral problems.

All children born before 32 gestational weeks or with a birth weight lower than 1,500 g were registered into the National Registry of the Swiss Neonatal Network. A pediatrician specialized in development examined these children at the age of 2 and 5 years. Their neurological development was assessed using the BSID-II [15] (between 2006 and 2012) or Bayley-III [16] (afterward). The study was approved by the Ethics Committee Zurich (KEK-ZH No. 2017-01268). Written informed consent was obtained from the parents of each child.

\section{Statistics}

Quantitative data are presented as medians with minimum and maximum values, or mean \pm SD. Percentages are given for the results of categorical variables. The Shapiro-Wilk test was performed to check for normal distribution. The $t$-test or Mann-Whitney $\mathrm{U}$ test was used as appropriate. $\chi^{2}$ test was used to compare 2 popula- 
Table 1. Event-free survival and neurological long-term outcome

\begin{tabular}{lccc}
\hline & $\begin{array}{c}\text { Laser group } \\
(N=42)\end{array}$ & $\begin{array}{c}\text { Control group } \\
(N=32)\end{array}$ & $p$ value \\
\hline Age at time of assessment, months & $50(7-111)$ & $60(31-116)$ & 0.14 \\
Event-free survival, $n(\%)$ & $32(76)$ & $24(75)$ & 0.91 \\
Neurological anomalies, $n(\%)$ & $5(12)$ & $3(9)$ & 1.0 \\
CP, $n(\%)$ & $2(5)$ & $0(0)$ & 0.5 \\
Epilepsy, $n(\%)$ & $1(2)$ & $0(0)$ & 1.0 \\
Other SM findings, $n(\%)$ & $3(7)$ & $3(9)$ & 1.0 \\
SDQ test, $n(\%)$ & $N=39$ & $N=28$ & \\
$\quad$ Values $\geq 14$ (at risk) & $4(10)$ & $1(4)$ & 0.39 \\
Bayley test (II or III), $n(\%)^{\mathrm{a}}$ & $N=15$ & $N=16$ & \\
$\quad$ Values $<85$ & $4(27 \%)$ & $7(44 \%)$ & 0.32 \\
$\quad$ Values $<70$ & $2(13 \%)$ & $3(19 \%)$ & 1.0 \\
\hline
\end{tabular}

SM, sensorimotor; SDQ, Strengths and Difficulties Questionnaire; GW, gestational weeks; CP, cerebral palsy. ${ }^{\text {a }}$ Children born before $32 \mathrm{GW}$ or/and with a birth weight lower than $1,500 \mathrm{~g}$.

Table 2. Detailed information about the children with neurological findings

\begin{tabular}{|c|c|c|c|c|c|c|c|}
\hline $2(\mathrm{~L})$ & Male, $1,650 \mathrm{~g}, 42.5 \mathrm{~cm}, 4-66$ & 3 & $315 / 7$ & $\begin{array}{l}\text { Hemorrhage grade I, cystic leukomalacia } \\
\text { grade II, contralateral ischemia }\end{array}$ & 18 & BSID II: 50/49 & CP, epilepsy \\
\hline $4(\mathrm{~L})$ & Female, $990 \mathrm{~g}, 36 \mathrm{~cm}, 5-7-8$ & 1 & $301 / 7$ & Normal & Normal & Normal & $\begin{array}{l}\text { SM } \\
\text { abnormalities }\end{array}$ \\
\hline $5(\mathrm{~L})$ & Female, $1,280 \mathrm{~g}, 39 \mathrm{~cm}, 8-6-8$ & 3 & $286 / 7$ & Increased periventricular echogenicity & Normal & BSID III: 125/112/- & $\mathrm{CP}$ \\
\hline $3(\mathrm{C})$ & Female, $1,260 \mathrm{~g}, 40 \mathrm{~cm}, 7-9-9$ & - & $295 / 7$ & Dilated lateral ventricles & 14 & BSID II: $86 / 84$ & $\begin{array}{l}\text { SM } \\
\text { abnormalities }\end{array}$ \\
\hline
\end{tabular}

1 (L) Laser coagulation had to be terminated due to bleeding, and IUFD occurred. 2 (L) and 3 (L) are siblings. L, Laser; C, Control; SDQ, Strengths and Difficulties Questionnaire; BSID, Bayley Scales of Infant Development, version II or III, normative value for each score 100 \pm 15 ; CP, cerebral palsy; SM, sensorimotor; GA, gestational age; GW, gestational weeks.

tions when the theoretical numbers were $>5$, and Fisher's exact test was used when the theoretical numbers were $<5$.

Univariate and multivariate logistic regression analyses were performed to identify independent predictors for event-free survival. Odds ratio and $95 \%$ confidence intervals were provided. A $p$ value $<0.05$ was considered statistically significant. The statistical analysis was performed using SPSS (IBM SPSS Statistics version 22, Zurich, Switzerland).

\section{Results}

For the long-term outcome, we had data from 25 mothers and 42 children treated with laser therapy and 16 mothers with 32 children in the control group. When comparing the included and excluded children, there was no significant difference between the children excluded 
Table 3. Multiple regression analysis

\begin{tabular}{lccc}
\hline & Mean \pm SD & $N(\%)$ & $p$ value \\
\hline GA at delivery - GW & $32.8 \pm 3.2$ & & $<\mathbf{0 . 0 0 1}$ \\
Sex & & $43(58 \%)$ & 0.77 \\
$\quad$ Female & & $31(42 \%)$ & \\
$\quad$ Male & & $\mathbf{0 . 0 0 4}$ \\
Birth-weight, g & $1,812 \pm 725$ & & $\mathbf{0 . 0 0 3}$ \\
Birth-length, cm & $42 \pm 5$ & $\mathbf{0 . 0 1 6}$ \\
Apgar 5 min & $9(3-10)$ & $p$ value \\
\hline & OR (95\% CI) & $\mathbf{0 . 0 4 4}$ \\
\hline GA at delivery, GW & $1.73(1.01-2.94)$ & \\
\hline
\end{tabular}

GA, gestational age; GW, gestational weeks.

due to loss of follow-up or insufficient German language skills regarding GA at birth $(p=0.19)$, birth weight ( $p=$ $0.11)$, or 5-min Apgar $(p=0.09)$. There was a significant difference in GA at birth in cases where pregnancy was lost $(p<0.001)$ compared to the included cases. Maternal age was similar in all included and excluded cases $(p=$ $0.76)$.

For the control group, we had questionnaires filled out by the parents from 22 children, and in the remaining 10 children, we had the data from the Registry of the Swiss Neonatal Network. This explains why in some cases the SDQ (questionnaire) and in other cases the BSID-II (Swiss Neonatal Network) are listed. The secondary endpoints such as school career, special therapy or requirement of special aid or other assistive equipment, and freetime activities of the children were also assessed with the questionnaire filled out by the parents.

\section{Primary Outcome}

Table 1 presents the event-free survival rates and the neurological long-term outcome of the children. Eventfree survival, neurodevelopmental long-term outcome, and behavioral outcome were similar in both groups. In the laser group, there were 2 children with $\mathrm{CP}$ - one of them was also diagnosed with epilepsy. Of the $76 \%$ children with an event-free survival, $40 \%$ were initially diagnosed with Quintero 1 or 2 and 36\% with Quintero 3 or 4. There was no statistically significant difference in the event-free survival according to Quintero stages within the laser group $(p=0.7)$.

Detailed information about the 8 children with neurological findings is presented in Table 2 . In cases 1,3 , and 4 of the laser group and in case 2 of the control group, the
Table 4. Maternal and neonatal baseline characteristics

\begin{tabular}{|c|c|c|c|}
\hline & $\begin{array}{l}\text { Laser } \\
\text { group }\end{array}$ & $\begin{array}{l}\text { Control } \\
\text { group }\end{array}$ & $\begin{array}{l}p \\
\text { value }\end{array}$ \\
\hline Maternal characteristics & $(N=25)$ & $(N=16)$ & \\
\hline Age & $29(23-41)$ & $36(29-40)$ & 0.02 \\
\hline \multicolumn{4}{|l|}{ Ethnicity, $n(\%)$} \\
\hline Caucasian & $23(92 \%)$ & $14(87.5 \%)$ & \multirow{4}{*}{0.64} \\
\hline Hispanic & $1(4 \%)$ & $2(12.5 \%$ & \\
\hline Asian & $1(4 \%)$ & $0(0 \%)$ & \\
\hline Black & $0(0 \%)$ & $0(0 \%)$ & \\
\hline \multicolumn{4}{|l|}{ Socioeconomic status, $n(\%)$} \\
\hline Upper level & $4(16 \%)$ & $9(56 \%)$ & 0.007 \\
\hline Intermediate level & $8(32 \%)$ & $3(19 \%)$ & 0.49 \\
\hline Basic level & $3(12 \%)$ & $3(19 \%)$ & 0.66 \\
\hline Lower level & $0(0 \%)$ & $0(0 \%)$ & - \\
\hline Students & $0(0 \%)$ & $0(0 \%)$ & - \\
\hline Homemaker & $10(40 \%)$ & $1(6 \%)$ & 0.03 \\
\hline \multicolumn{4}{|l|}{ Survival rates } \\
\hline Survival $1, n(\%)$ & $8(32 \%)$ & $0(0 \%)$ & \multirow[t]{2}{*}{0.01} \\
\hline Survival $2, n(\%)$ & $17(68 \%)$ & $16(100 \%)$ & \\
\hline Neonatal characteristics & $(N=42)$ & $(N=32)$ & \\
\hline GA at delivery, GW & $32.8 \pm 3.0$ & $32.85 \pm 3.6$ & 0.95 \\
\hline Weight, g & $1,888 \pm 741$ & $1,714 \pm 702$ & 0.31 \\
\hline Length, $\mathrm{cm}$ & $42.2 \pm 4.7$ & $41.6 \pm 5.3$ & 0.63 \\
\hline Head circumference, $\mathrm{cm}$ & $30.3 \pm 3.4$ & $29.8 \pm 3.3$ & 0.60 \\
\hline Umbilical artery-pH & $7.30 \pm 0.06$ & $7.31 \pm 0.06$ & 0.58 \\
\hline Apgar, $5 \mathrm{~min}$ & $8(3-10)$ & $9(3-10)$ & 0.08 \\
\hline Sex (female), $n(\%)$ & $26(62)$ & $17(53)$ & 0.45 \\
\hline \multicolumn{4}{|c|}{ Neonatal complications, $n(\%)$} \\
\hline RDS & $28(67)$ & $17(53)$ & 0.24 \\
\hline NEC & $2(5)$ & $0(0)$ & 0.50 \\
\hline Sepsis & $3(7)$ & $1(3)$ & 0.62 \\
\hline ROP & $1(2)$ & $0(0)$ & 1.0 \\
\hline Oxygen $>36$ days & $4(10)$ & $1(3)$ & 0.37 \\
\hline Brain lesion & $1(2)$ & $0(0)$ & 1.0 \\
\hline \multicolumn{4}{|l|}{ Death within first } \\
\hline 30 days of life, $n(\%)$ & $0(0)$ & $0(0)$ & - \\
\hline
\end{tabular}

GA, gestational age; GW, gestational weeks; RDS, respiratory distress syndrome; NEC, necrotising enterocolitis; ROP, retinopathy of prematurity.

cranial ultrasound controls were normal at the time of assessment.

A univariate regression analysis was performed and identified GA at delivery $(p<0.001)$, birth weight $(p=$ $0.004)$, birth length (0.003), and Apgar score at $5 \mathrm{~min}$ $(0.016)$ as possible independent predictive factors for an event-free survival. The multiple logistic regression analysis showed that only GA at delivery was a predictive factor for event-free survival $(p=0.044)$ (Table 3).

Maternal and neonatal baseline characteristics of the laser group and the control group are shown in Table 4 . 
Table 5. School career, special therapy, and special aid equipment

\begin{tabular}{|c|c|c|c|}
\hline School career & $\begin{array}{l}\text { Laser group } \\
(N=42), n(\%)\end{array}$ & $\begin{array}{l}\text { Control group } \\
\left(N=22^{\mathrm{a}}\right), n(\%)\end{array}$ & $\begin{array}{l}p \\
\text { value }\end{array}$ \\
\hline No school $^{\mathrm{a}}$ & $24(57)$ & $12(55)$ & 0.84 \\
\hline Kindergarten $^{\mathrm{a}}$ & 7 (17) & $2(9)$ & 0.47 \\
\hline School $^{\mathrm{a}}$ & $11(26)$ & $8(36)$ & 0.40 \\
\hline Skip a class ${ }^{\mathrm{a}}$ & $0(0)$ & $0(0)$ & - \\
\hline Remedial teaching $^{\mathrm{a}}$ & $4(10)$ & $0(0)$ & 0.29 \\
\hline Special school $^{\mathrm{a}}$ & $0(0)$ & $0(0)$ & - \\
\hline Language school $^{\mathrm{a}}$ & $0(0)$ & $0(0)$ & - \\
\hline Therapy & $12(29)$ & $13(41)$ & 0.28 \\
\hline Speech therapy & $2(5)$ & $1(3)$ & 0.56 \\
\hline Physical therapy & $11(26)$ & $10(31)$ & 0.63 \\
\hline $\begin{array}{l}\text { Psychomotoric } \\
\text { therapy }\end{array}$ & $1(2)$ & $0(0)$ & 1.0 \\
\hline $\begin{array}{l}\text { Early support/ } \\
\text { education }\end{array}$ & $4(10)$ & $0(0)$ & 0.13 \\
\hline Curative education & $2(5)$ & $2(6)$ & 1.0 \\
\hline Special aids ${ }^{\mathrm{a}}$ & $5(12)$ & $0(0)$ & 0.16 \\
\hline Hearing aid ${ }^{\mathrm{a}}$ & $0(0)$ & $0(0)$ & - \\
\hline Glasses $^{\mathrm{a}}$ & $3(7)$ & $0(0)$ & 0.56 \\
\hline Walking aid ${ }^{\mathrm{a}}$ & $2(5)$ & $0(0)$ & 0.54 \\
\hline Splint ${ }^{\mathrm{a}}$ & $1(2)$ & $0(0)$ & 1.0 \\
\hline
\end{tabular}

a Only answered in questionnaire, available for 22 children in the control group.

Eleven children were initially classified as Quintero 1, 12 as Quintero 2, 17 as Quintero 3, and 2 as Quintero 4. There was no significant difference in the neonatal baseline characteristics or the perinatal morbidity between the 2 groups.

\section{Secondary Outcome}

School Career, Therapy, and Need for Special Aid

Equipment

Information on school career, need for special therapy, or requirement of special aid equipment is shown in Table 5. There was no significant difference between the laser and the control group. No child of both groups repeated a class, and only 4 children $(10 \%)$ of the laser group needed remedial teaching $(p=0.13)$. The most frequent therapy was physical therapy in both groups (26 vs. $31 \%, p=0.63)$. Five children in the laser group (12\%), but none in the control group, required special aid equipment $(p=0.16)$.

\section{Free-Time Activities}

The children in the control group had more hobbies than the children in the laser group ( 86 vs. $57 \%, p=0.018$ ). The most frequent sports were gymnastics, swimming, soccer, and other ball sports such as volleyball or tennis. Skiing, horseback riding, kung fu, and karate were also mentioned. The musically active children either played an instrument (piano, flute, or violin) or were singing in a choir. More children from the laser group needed a break during sports than children in the control group ( 21 vs. $0 \%, p=0.02$ ), and fewer children from the laser group were able to keep up while doing sports (69 vs. $100 \%, p=0.003)$.

\section{Discussion}

The present study shows that the rate of event-free long-term outcome, including school career, therapies, or special aid equipment, in monochorionic twins after FLS is comparable to that of dichorionic twins who did not have any invasive intervention during pregnancy and that only the GA at delivery seems to be a predictive factor for event-free survival. Overall, neurological anomalies were found in $12 \%$ in the laser group and in $9 \%$ in the control group. CP was diagnosed in $5 \%$ of the laser group. Children without FLS were involved in more free-time activities and needed fewer breaks during physical activity than children with FLS during pregnancy.

The presented results are comparable to other international studies. Banek et al. [22] also studied the long-term neurodevelopmental outcome of twins after intrauterine laser surgery for TTTS. The 89 children included in their study underwent physical and neurological examination; $78 \%$ of the children showed normal development, $11 \%$ had minor neurological anomalies, and another $11 \%$ had major neurological deficiencies. Also, Lenclen et al. [9] studied the neurodevelopmental outcome of children after laser therapy. The children were assessed at 2 years of age corrected for prematurity. The assessment was performed using an Ages and Stages Questionnaire (ASQ) and a neurological assessment [9]. They compared the neurological outcome and the results of the ASQ with a group of dichorionic children. Considering the neurological impairment, there was no significant difference between the children treated with FLS and dichorionic children; the rate for normal neurological development was 88.6 and $93.6 \%$, respectively [9]. They also found that low GA was the only significant factor associated with neurological impairment in twins treated with laser therapy due to TTTS [9]. Lopriore et al. [23] compared monochorionic twins with TTTS and laser therapy with monochorionic twins without TTTS. They described a significant higher incidence of severe cerebral lesions in twins with 
TTTS than in monochorionic twins without TTTS (10 vs. $2 \%, p=0.02)[23]$.

In a review, van Klink et al. [24] discusses results on the long-term outcome of TTTS survivors, treated with either amnioreduction or FLS. For the FLS group, they analyzed 13 studies from 1999 to 2015 [24]. Their numbers for $\mathrm{CP}$ ranged from $2 \%$ to $12 \%$, which are also comparable to our findings ( 2 children, $5 \%$ ). They mentioned a higher Quintero stage as a risk factor for neurodevelopmental impairment [24]. We, on the other hand, did not find a difference between Quintero stages 1 and 2 and 3 and 4 within the laser group.

Another current systematic review from MirallesGutiérrez et al. [25], which included 9 studies with sample sizes ranging from 56 to 318 , described a mean incidence of neurological anomalies at 24 months of age after laser therapy in $14 \%$. CP was described in about $6 \%$ of the children treated with laser therapy [25]. The children in our group were older at the time of assessment (24 months [25] vs. 50 months), but the results are similar. The review from Miralles-Gutiérrez et al. [25] did not find a clear correlation between neurological complications and a higher Quintero stage.

Hack et al. [26] also compared the long-term neurodevelopmental outcome of monochorionic twins with matched dichorionic twins. They used the same following matching criteria: GA at delivery, gender, birth weight, and ethnicity [26]. They also did not describe any significant differences between the monochorionic and dichorionic twins except a slight delay in language and hearing development in monochorionic twins [26].

There was no significant difference regarding school career, need of special therapy, or requirement of special aid equipment in our cohort. Physical therapy was the most frequent therapy in both groups. The only differences between the 2 groups were that children from the control group were participating in more free-time activities and needed less breaks during physical activity than children from the laser group. These observations can be explained by the fact that control children were older than children in the laser group at the assessment period, and so possibly were already more involved in after-school activities. While these 2 findings could be related to a reduced physical endurance of children in the laser group in comparison with controls, the absence of a difference regarding the event-free survival between the 2 groups does not support this hypothesis. Since reports on this outcome in similar cohorts as in our study are lacking, no comparison of these findings with data from the literature is possible.

Long-Term Outcome after Fetoscopic Laser Therapy van Klink et al. [27] compared the neurodevelopmental outcome at 2 years between twins with TTTS treated with either the Solomon technique or standard laser surgery. They also compared early interventions such as physical therapy, speech-language therapy, and psychological interventions between the 2 groups. There were no significant differences in the mentioned early interventions between the 2 groups [27]. Physical therapy was performed in 39\% for the Solomon group and $41 \%$ for the standard group [27]; 9 and $12 \%$ needed speech-language therapy [27]. In our laser group, $26 \%$ of the children needed physical therapy and in 5\% speech therapy was necessary. School career was comparable in both groups. Children without FLS were involved in more free-time activities and needed fewer breaks during physical activity than children with FLS during pregnancy. We found no studies that looked at school career and children's free-time activities.

\section{Limitations}

The small sample size of the laser and the control group, a selection bias due to the excluded cases, and the retrospective design of the analysis are the 3 main limitations of this study, which could have limited the generalizability of the results.

\section{Strengths}

The strength of this study is the analysis of the longterm outcome after laser therapy, including their school career, need for therapy and special aid equipment, and free-time activities, and not only the survival rates of the children in a well-monitored Swiss cohort. The knowledge of their school career and their leisure time activities is an important part in counselling parents who are diagnosed with TTTS during pregnancy. To our knowledge, this is the only study that also compared parameters such as school career, therapies, need for special aid equipment, and leisure time activities between children treated with FLS and their control group, consisting of twins and not only singleton pregnancies.

\section{Conclusion}

In the present study sample, the outcome of monochorionic twins treated with FLS was comparable to the outcome of dichorionic twins without invasive treatment. Long-term neurodevelopmental outcome in the cohort was mainly dependent on GA at birth. 


\section{Statement of Ethics}

The research was conducted ethically in accordance with the World Medical Association Declaration of Helsinki and with the approval of the ethics commission Zurich (KEK-ZH Nr. 201701268). Subjects (parents for their children) gave their written informed consent. The authors have no ethical conflicts to disclose.

\section{Conflict of Interest Statement}

The authors have no conflicts of interest to declare.

\section{Funding Sources}

There was no funding for this study. Giancarlo Natalucci was supported by the Swiss National Science Foundation (Grant: PZOOP3_161146).

\section{Author Contributions}

All authors contributed to the conception and design of the study. N.O., G.N., and L.R. were responsible for the acquisition, analysis, and interpretation of all data. G.N., N.O., and L.R. drafted the manuscript, which was critically revisited by R.Z., M.H., and F.K. Finally, all authors approved the manuscript.

\section{References}

1 Lewi L, Van Schoubroeck D, Gratacós E, Witters I, Timmerman D, Deprest J. Monochorionic diamniotic twins: complications and management options. Curr Opin Obstet Gynecol. 2003;15(2):177-94.

2 Lewi L, Jani J, Deprest J. Invasive antenatal interventions in complicated multiple pregnancies. Obstet Gynecol Clin North Am. 2005;32(1):105-26.

3 Baud D, Windrim R, Van Mieghem T, Keunen J, Seaward G, Ryan G. Twin-twin transfusion syndrome: a frequently missed diagnosis with important consequences. Ultrasound Obstet Gynecol. 2014;44(2):205-9.

4 Senat MV, Deprest J, Boulvain M, Paupe A, Winer N, Ville Y. Endoscopic laser surgery versus serial amnioreduction for severe twinto-twin transfusion syndrome. N Engl J Med. 2004;351(2):136-44.

5 Cincotta RB, Gray PH, Gardener G, Soong B, Chan FY. Selective fetoscopic laser ablation in 100 consecutive pregnancies with severe twin-twin transfusion syndrome. Aust N Z J Obstet Gynaecol. 2009;49(1):22-7.

6 Quintero RA, Dickinson JE, Morales WJ, Bornick PW, Bermúdez C, Cincotta $\mathrm{R}$, et al. Stage-based treatment of twin-twin transfusion syndrome. Am J Obstet Gynecol. 2003; 188(5):1333-40.

7 Akkermans J, Peeters SH, Klumper FJ, Lopriore E, Middeldorp JM, Oepkes D. Twenty-five years of fetoscopic laser coagulation in twin-twin transfusion syndrome: a systematic review. Fetal Diagn Ther. 2015; 38(4):241-53.

8 Rüegg L, Hüsler M, Krähenmann F, Natalucci G, Zimmermann R, Ochsenbein-Kölble N. Outcome after fetoscopic laser coagulation in twin-twin transfusion syndrome: is the survival rate of at least one child at 6 months of age dependent on preoperative cervical length and preterm prelabour rupture of fetal membranes? J Matern Fetal Neonatal Med. 2020; 38:852-60.

9 Lenclen R, Ciarlo G, Paupe A, Bussieres L, Ville Y. Neurodevelopmental outcome at 2 years in children born preterm treated by am- nioreduction or fetoscopic laser surgery for twin-to-twin transfusion syndrome: comparison with dichorionic twins. Am J Obstet Gy necol. 2009;201(3):291-5.

10 van Klink JM, Koopman HM, van Zwet EW, Oepkes D, Walther FJ, Lopriore E. Cerebral injury and neurodevelopmental impairment after amnioreduction versus laser surgery in twin-twin transfusion syndrome: a systematic review and meta-analysis. Fetal Diagn Ther. 2013;33(2):81-9.

11 Largo RH, Pfister D, Molinari L, Kundu S, Lipp A, Duc G. Significance of prenatal, perinatal and postnatal factors in the development of AGA preterm infants at five to seven years. Dev Med Child Neurol. 1989;31(4): 440-56.

12 Quintero RA, Morales WJ, Allen MH, Bornick PW, Johnson PK, Kruger M. Staging of twin-twin transfusion syndrome. J Perinatol. 1999;19(8 Pt 1):550-5.

13 Slaghekke F, Oepkes D. Solomon technique versus selective coagulation for twin-twin transfusion syndrome. Twin Res Hum Genet. 2016;19(3):217-21.

14 Christine C, Dolk H, Platt MJ, Colver A Prasauskiene A, Krägeloh-Mann I, et al. Recommendations from the SCPE collaborative group for defining and classifying cerebral palsy. Dev Med Child Neurol Suppl. 2007; 109:35-8

15 Bayley N. Bayley scales of infant development. 2nd ed. San Antonio, TX: The Psychological Corporation; 1993.

16 Bayley N. Bayley scales of infant and toddler development. 3rd ed. San Antonio, TX: Psychological Corporation; 2006.

17 Schlapbach LJ, Adams M, Proietti E, Aebischer M, Grunt S, Borradori-Tolsa C, et al. Outcome at two years of age in a Swiss national cohort of extremely preterm infants born between 2000 and 2008. BMC Pediatr. 2012;12: 198

18 Papile LA, Munsick-Bruno G, Schaefer A. Relationship of cerebral intraventricular hemorrhage and early childhood neurologic handicaps. J Pediatr. 1983;103(2):273-7.
19 Goodman R. The strengths and difficulties questionnaire: a research note. J Child Psychol Psychiatry. 1997;38(5):581-6.

20 Goodman R. Psychometric properties of the strengths and difficulties questionnaire. J Am Acad Child Adolesc Psychiatry. 2001;40(11): 1337-45.

21 Woerner W, Becker A, Friedrich C, Klasen H, Goodman R, Rothenberger A. [Normal values and evaluation of the German parents' version of Strengths and DIfficulties Questionnaire (SDQ): results of a representative field study]. Z Kinder Jugendpsychiatr Psychother. 2002;30(2):105-12.

22 Banek CS, Hecher K, Hackeloer BJ, Bartmann P. Long-term neurodevelopmental outcome after intrauterine laser treatment for severe twin-twin transfusion syndrome. Am J Obstet Gynecol. 2003;188(4):876-80.

23 Lopriore E, van Wezel-Meijler G, Middeldorp JM, Sueters M, Vandenbussche FP, Walther FJ. Incidence, origin, and character of cerebral injury in twin-to-twin transfusion syndrome treated with fetoscopic laser surgery. Am J Obstet Gynecol. 2006;194(5):1215-20.

24 van Klink JM, Koopman HM, Rijken M, Middeldorp JM, Oepkes D, Lopriore E. Longterm neurodevelopmental outcome in survivors of twin-to-twin transfusion syndrome. Twin Res Hum Genet. 2016;19(3):255-61.

25 Miralles-Gutiérrez A, Narbona-Arias I, González-Mesa E. Neurological complications after therapy for fetal-fetal transfusion syndrome: a systematic review of the outcomes at 24 months. J Perinat Med. 2018; 46(9):991-7.

26 Hack KE, Koopman-Esseboom C, Derks JB, Elias SG, de Kleine MJ, Baerts W, et al. Longterm neurodevelopmental outcome of monochorionic and matched dichorionic twins. PLoS One. 2009;4(8):e6815.

27 van Klink JM, Slaghekke F, Balestriero MA, Scelsa B, Introvini P, Rustico M, et al. Neurodevelopmental outcome at 2 years in twintwin transfusion syndrome survivors randomized for the Solomon trial. Am J Obstet Gynecol. 2016;214(1):113, 7. 